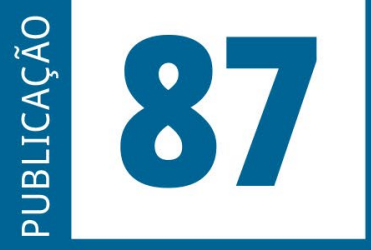

ISSN: 0101-9562

ISSN ELETRÔNICO: 2177-7055

SEQÜENCIA

Publicação do

Programa de Pós-Graduação em Direito da UFSC

VOLUME 42 - ANO 2021
Estudos jurídicos e políticos 
SEQUÊNCIA - ESTUDOS JURÍDICOS E POLÍTICOS é uma publicação temática e de periodicidade quadrimestral, editada pelo Programa de Pós-Graduação Stricto Sensu em Direito da Universidade Federal de Santa Catarina - UFSC.

SEQUÊNCIA - ESTUDOS JURÍDICOS E POLÍTICOS is a thematic publication, printed every four months, edited by the Program in law of the Federal University of Santa Catarina - UFSC.

Versão eletrônica: http://www.periodicos.ufsc.br/index.php/sequencia

A publicação é indexada nas seguintes bases de dados e diretórios/

The Publication is indexed in the following databases and directories:

Base OJS

Base PKP

CCN (Catálogo Coletivo Nacional)

Dialnet

DOAJ (Directory of Open Access Journals)

EBSCOhost

Genamics Journalseek

ICAP (Indexação Compartilhada de Artigos de Periódicos)

Latindex

LivRe!

OJS
PKP
Portal de Periódicos UFSC
Portal do SEER
ProQuest
SciELO
Sherpa/Romeo
Sumarios.org
ULRICH'S
vLex

Ficha catalográfica

Seqüência: Estudos jurídicos e políticos. Universidade Federal de Santa Catarina.

Programa de Pós-Graduação em Direito. n.1 (janeiro 1980)-.

Florianópolis: Fundação José Boiteux. 1980-.

Publicação contínua

Resumo em português e inglês

Versão impressa ISSN 0101-9562

Versão on-line ISSN 2177-7055

1. Ciência jurídica. 2. Teoria política. 3. Filosoia do direito. 4. Periódicos.

I. Universidade Federal de Santa Catarina. Programa de Pós-graduação em

Direito

CDU 34(05)

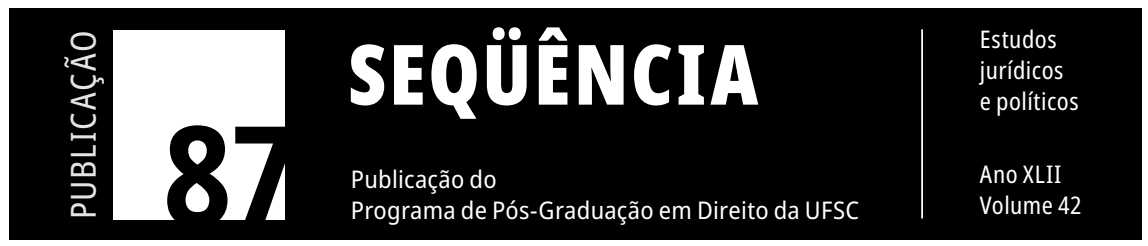




\section{Direitos da Personalidade e o Jetztzeit: uma análise a partir das teses XVI e XVIII sobre 0 conceito de história de Walter Benjamin}

\section{Personality Rights and the Jetztzeit: an analysis based on theses XVI and XVIII on Walter Benjamin's concept of history}

Dirceu Pereira Siqueira

Universidade Cesumar, Maringá, Brasil

Fausto Santos de Morais

Faculdade Meridional - IMED,

Passo Fundo, Brasil

Fernando Rodrigues de Almeida

Universidade Cesumar, Maringá, Brasil

RESUMO: O presente trabalho tem como objetivo analisar dois fragmentos da obra de Walter Benjamin - quais sejam as teses XVI e XVIII - como paradigma de definição sobre o conceito de personalidade, que se apresenta com um caráter de natureza dúbia no Estado de Direito. Uma vez que os Direitos da Personalidade, por terem em si uma defesa de caráter intrínseco a indivíduo apresentam-se com um meio de determinação jusnaturalista para serem definidos em um racionalismo juspositivista. O presente trabalho não tem o intuito de esgotar o tema, mas apresentar uma hipótese que deverá ser deduzida por meio de apresentação teórico-bibliográfica.

Palavras-Chave: Direitos da Personalidade - Juspositivismo - Messianismo Walter Benjamin.

ABSTRACT: this work aims to analyze two fragments of Walter Benjamin's wirke namely theses XVI and XVIII - as a paradigm of definition about the concept of personality, which presents itself with a dubious nature in the rule of law. Since Personality Rights have a defense of an intrinsic character to the individual, present themselves with a means of jusnaturalistic determination to be defined in a 
juspositivist rationalism. The present work does not intend to exhaust the topic but to present a hypothesis that should be deduced through theoretical-bibliographic presentation.

KEYWORDS: Personality Rights - Juspositivism - Messianism - Walter Benjamin.

\section{INTRODUÇÃO}

Os Direitos da Personalidade são defendidos no estado de direito como formas de garantia de direitos intrínsecos ao indivíduo e, ao mesmo tempo, ocupam um local contratual na teoria civilista do direito. Por mais que alguns autores tentem o categorizar em uma estrutura constitucionalista, a personalidade é pacificamente atribuída a um direito civil determinado.

Entretanto, justamente por isso sua categoria contratual se colide com o elemento jusnaturalista de objeto que emana do indivíduo, uma vez que, segundo a aplicação da metodologia purista do direito, aplicável ao Estado de Direito da democracia parlamentar liberal, o indivíduo deve ser despersonalizado para a formação de um conjunto de normas denominados como sujeito de direito.

Para análise desse paradoxo, o presente trabalho, inicialmente se proporá a observar a personalidade jurídica como modelo normativo racional, passando pela observação da teoria das ciências da psicologia, para um auxílio na hermenêutica da natureza de tais direitos.

Após isso, será necessária a entrada na literatura de Walter Benjamin, a partir de duas de suas teses sobre o conceito de história. Inicialmente observando a relação do tempo, observando como progressismo e a linearidade temporal agem sobre os direitos da personalidade e como se dão em sua referência com o sujeito.

Após isso será possível, a partir da tese XVI, observar como a abertura de uma espaço contra-temporal, denominado messianismo benjaminiano, a partir de um misticismo teológico-judaico, pode trazer a realização de uma personalidade fora dos paradigmas apresentados pelo direito, para melhor categorizar suas necessidades de 
emancipação, observando os revezes da racionalidade jurídica e suas fronteiras de enfrentamento.

O presente trabalho deduz sua hipótese a partir de pesquisa bibliográfica, alternando elementos jurídicos com perspectivas filosóficas e um ponto de observação teórico a partir de elementos teológicos na filosofia de Walter Benjamin.

\section{PERSONALIDADE JURÍDICA E SUA PARADOXAL NATUREZA JUSNATURALISTA-POSITIVISTA: UM PROBLEMA SOBRE A HISTÓRIA LINEAR}

Os direitos da personalidade trazem um conceito muito dúbio na ordem do direito, ainda mais quando estamos diante de um sistema jurídico aplicado por meio de um purismo metodológico positivista, isto é, por mais que haja elucubrações normativas acerca de uma suposta "superação" da ordem positivista kelseniana, algumas até chamadas de pós-positivismo, isso acaba implicando nos mesmo problema da justificação dos pós-modernos, ou seja, pressupor que há espaço, dentro dos moldes atuais de superação de uma racionalidade inaugurada com o deslocamento da justiça para o sujeito, em outras palavras, uma superação da racionalidade.

Isso não parece cabível ao se observar os paradigmas que se encontram no modelo jurídico e estatal na atualidade, de fato, a racionalidade apresenta-se como estrutura medular de todo o debate jusfilosófico e político, ainda que conceitos que remetam a um naturalismo ou um retorno a uma teologização do espaço público, ainda há nos próprios debates um elemento secularizador imóvel, o qual apresenta-se como a racionalidade aos métodos kantianos.

Nesse ponto apresenta-se um primeiro problema com a ideia de personalidade como elemento normativo. A personalidade confunde-se, ainda que nos estudos acadêmicos com um paradigma muito próximo a uma inerência do sujeito, sujeito este de direito, que por 
conseguinte dá uma abertura a interpretação de um direito natural justificado no elemento personalíssimo que, ao mesmo tempo, se encontra em um estigma civilista, pressuposto por uma atividade contratual.

Simultaneamente, nos autores mais conservadores sobre os direitos da personalidade, ao mesmo tempo que se estatui o conceito de personalidade como inerência ao indivíduo, ou seja, a partir de um método purista kelseniano que propõe um isolamento racionalista do direito em um dever-ser puro, em que o conteúdo da norma se fundamenta na sua validade, assim, é sua forma que conduz o elemento de aplicação ao fenômeno, parece aqui um paradoxo a aplicação de axiologia a própria forma do direito da personalidade. Dentre vários exemplos, destaca-se um, de Gustavo Trepedino, por sua relevância no tema em debate no âmbito da teoria do direito no Brasil:

Dito diversamente, considerada como sujeito de direito, a personalidade não pode ser dele o seu objeto. Considerada, ao revés, como valor, tendo em conta o conjunto de atributos inerentes e indispensáveis ao ser humano (que irradiam da personalidade), constituem bem jurídicos em si mesmos, dignos de tutela privilegiada (TrePENDINO, 1999, p. 27)

Observe-se que, a afirmação de definição da natureza dos direitos da personalidade encontra-se fundamentada em âmbitos de natureza jurídica diversa, enquanto atribuído ao sujeito de direito, categoria normativa e purista, o valor é inerente, o que se comunica com o indivíduo, categoria naturalista e valorativa. A indispensabilidade ao indivíduo e sua irradiação de necessidades personalíssimas são atribuídas como bem jurídicos, o que torna o tema mais ligado ao jusnaturalismo, enquanto os atributos passam a ser necessários de positivação por um objeto de relação hipotética do positivismo.

Dentro da perspectiva estatal de empenho da defesa dos direitos da personalidade o cenário é parecido, uma vez que, o limiar que compõe esses direitos são, por muitas vezes colocados no patamar de direitos fundamentais, essa estrutura apresenta-se de forma 
muito delicada, uma vez que, em tese, a natureza desses institutos, assinalados dentro de um estado de direito, são bem diversos entre si. Enquanto por um lado direitos fundamentais apresentam-se como garantias limitadoras de ação positiva do Estado sobre sua suplantação de direitos e retirada de autotutela dos indivíduos, ou seja, elemento contratual de garantia de liberdade frente a retirada parcial da liberdade por meio da força do pacta sunt servanda estatal, a personalidade por sua vez não se relaciona com garantia estatal, uma vez que emanado próprio indivíduo. Aqui então um problema, o indivíduo detentor de direitos fundamentais exprime-se por sujeito de direito, enquanto o indivíduo de personalidade exprime-se por sua própria autonomia.

Os teóricos mais responsáveis, que ainda pretendem garantir a personalidade como estatuto normativo, ainda que haja problemas quanto a sua definição, assumem a diferenciação entre tais campos e, ainda, colocam aos direitos da personalidade um caráter duplo de enquadramento de natureza, a fim de justificá-lo tanto na estrutura normativa quanto no âmbito do fenômeno. Cito Siqueira; Zanini (2018, p. 217):

De fato, a confluência entre o papel do Estado na sociedade contemporânea e a expressa previsão dos direitos da personalidade na Constituição e no Código Civil parece desenhar a ágora ideal para a defesa do caráter dúplice ou híbrido desses direitos.

Da mesma forma, na filosofia do direito, ainda encontramos essa dificuldade, enquanto observa-se a personalidade como elemento desligado da relação da autonomia axiológica do direito positivo, essa retirada implica neste um desvelamento de seu caráter anômico, ou seja, se tirado o conteúdo formal da norma do sujeito de direito, a fim de revelar a ele sua personalidade como objeto de fenômeno, este passa a ser um espaço de anomia normativa, assim, sendo indisponível a ser observado pelo plano do dever-ser, o que implicaria, necessariamente em uma disfunção do indivíduo existente e sua morte como sujeito jurídico. 
Diogo Félix e Gustavo Noronha de Ávila (2020, p. 994-995), vão além nesse paradigma, ligando uma amorfia do sujeito de direito, se desvelado tendo até mesmo sua autonomia da vontade dissuadida de seu plano do fenômeno, a partir da situação da forma jurídica em que se encontra o Estado de Direito:

Nesta perspectiva, o ser massificado é amorfo, não tem personalidade e se mostra indigno, dada a inexistência de relação autônoma entre ser e devir, ou seja, da relação entre ser que se é e devir que qualifica e aperfeiçoa a pessoa como um ser digno. A autonomia da vontade passa a ser utópica, restando neutralizada por completa, uma vez que, ao consumir, o sujeito ocupa seu papel do meio social, reconhecendo e fazendo-se por se reconhecer como membro pertencente a esse meio.

Talvez, possamos ainda buscar um refúgio de conceituar personalidade, antes de juridicamente, a partir das ciências específicas deste objeto. Estrutura muito comum e recomendada, uma vez que a abertura cognitiva do direito e seu fechamento estrutural têm resultado em, historicamente, uma entrada em searas específicas de outras áreas sem necessariamente aprovação científica ou qualquer aval de especialistas sobre tais fenômenos, vemos isso em relação a estruturação de aborto legal, estado puerperal, exame criminológico, enfim, diversos institutos jurídicos que não são cientificamente aceitos pelas áreas as quais tais conteúdos são estudados a fundo.

No caso aqui, a personalidade tem relação direta com as ciências da psicologia, as quais devemos dar ouvidos inicialmente antes de pensarmos em uma apropriação jurídica do conceito, o que talvez facilite a formalidade e o conteúdo a ser designado em um possível direito da personalidade.

Recorremos aqui ao clássico Teorias da personalidade de Jess e Gregory Feist e Tomi-Ann Roberts (2015, p. 4) o qual nos explica que os direitos da personalidade são estruturas individuais de reconhecimento psicológico de cada indivíduo, de forma que tais pessoas apresentam-se determinadas por traços específicos os quais “podemos 
dizer que personalidade é um padrão de traços relativamente permanentes e características únicas que dão consistência e individualidade aos comportamentos de uma pessoa".

Com isso, nosso trabalho se depara com uma condição complexa sobre positivação dos direitos, uma vez que, se o direito se determina como auto referência normativa, despersonalizando os sujeitos envolvidos a partir de um conjunto de normas, a apreciação da personalidade como traço individual dificulta sua aplicação. Isso porque a conduta humana regulada pela norma encontra seu fundamento na possibilidade de existência do sujeito como integrante do ordenamento. No plano da experiência, a norma interna é direcionada a conduta humana, porém, em razão da universalidade ser definida pelo espaço do poder, o sujeito a ser alcançado pela ordem jurídica deve ser estruturado também em um plano normativo pressuposto para que seja legítimo a ter seus atos autorizados pelo Estado. O sujeito, nesse sentido, deve, necessariamente, ser sujeito de direito, vez que sua própria existência deve ser "autorizada" no plano do dever-ser. Isso significa dizer que o ato de vontade normativo deve ser legitimado, da mesma forma que o poder e a existência de conceitos acessíveis pelo Estado, o que pode ser traduzido como ordenamento.

A teoria tradicional identifica o conceito de sujeito jurídico com o de pessoa. Eis a sua definição: pessoa é o homem enquanto sujeito de direitos e deveres. Dado que, porém, não só o homem mas também outras entidades, tais como certas comunidades como as associações, as sociedades por ações, os municípios, os Estados, são apresentados como pessoas, define-se o conceito de pessoa como "portador" de direitos e deveres jurídicos, podendo funcionar como portador de tais direitos e deveres não só o indivíduo mas também estas outras entidades. (KLesen, 1998, p. 120).

A importância da definição de pessoa como sujeito de direito é mister para a definição de capacidade de alcance normativo. Como dito anteriormente, a norma é produzida por atos de vontade, baseados 
em experiências, mas categorizados como funções abstratas pressupostas de um direito hierarquicamente superior. A lógica jurídica que define a capacidade de poder de um Estado deve se basear em uma definição de universalidade espacial normativa. Dessa forma, todo o alcance normativo deve vincular-se a capacidade do ordenamento. Assim, o sujeito de direito é também uma lógica normativa que tem sua possibilidade de vinculação a outras normas pelo fator de fazer parte, como norma, do espaço do poder.

Com isso, como seria possível desenvolver traços individuais por meio de uma estrutura legal positivadora? Esse não é nosso único problema, ainda sobre definição das ciências da psicologia sobre personalidade, observamos que, se o direito tem um caráter universalizador e difuso sobre o conceito normativo, a aplicação da personalidade nesse paradigma se torna ainda mais paradoxal quanto temos a situação que o conceito de personalidade não é universal entre os teóricos da área em questão, observemos:

No entanto, os teóricos não entraram em consenso quanto a uma definição única de personalidade. $\mathrm{Na}$ verdade, eles desenvolveram teorias singulares e vitais, porque não havia concordância quanto à natureza da humanidade e porque cada um via a personalidade de um ponto de referência individual. (Feist; Roberts, 2015, p. 4)

Ora, a necessidade de positivar normas por um método purista do positivismo ao tentar alcançar a personalidade certamente acaba por ter um efeito dubio ao revelar-se como norma uma vez que o própria conceito de personalidade não alcança em sua seara originária de estudos pacificidade científica universal, não se trata de um conceito único, apesar de ser pacífico o fato de que esta personalidade é um traço de determinação individual do sujeito, o que se enquadra como apropriação desses traços não pode ser determinado com uma única noção a ponto de tornar-se ou numerus clausus ou sequer conteúdo determinado por racionalidade jurídica em uma decisão judicial, 
justamente porque a possibilidade de contestação desse sistema se torna fácil por meio argumentativo.

De tal forma, observemos que, o direito mais uma vez acaba por, na necessidade de elaborar uma universalização do conceito de personalidade por aderir a conceitos de se dividem de sua ótica purista, o que por si é um problema, aqui, não mais para a personalidade, mas para a própria validade normativa.

A aproximação com conceitos de direito natural aproxima a aplicação da personalidade por um método científico do direito de ensaios metafísicos que se afastam da possibilidade racional kantiana do direito.

Dessa forma não há como não observar que a busca por uma unificação conceitual de direitos da personalidade trouxe a essa norma uma função de ilegitimidade normativa justamente por saltar dos limites da moldura semântica da norma e aproximar-se a conceitos que, de longe da qualidade científica, apresentam-se como hipóteses que por vezes tem seu sentido moral ou de suposição dedutiva, o que traz uma metafísica da personalidade o afastando justamente do seu conceito de direito, ou seja, apresentando problema quanto ao seu caráter de norma jurídica, o que preocupa ainda mais quando se tenta aproxima-los de um direito fundamental, que constitucionaliza um conceito axiológico do ser, sem estar presente em uma racionalidade principialista.

Esse paradigma pode nos ser auxiliado pela análise de Jacques Lancan sobre a polêmica da personalidade nas ciências da psicologia, uma vez que o paradigma de sua definição alcança patamares parecidos a disfunção do direito, uma vez que Lacan (2011, p. 19) afirma que a "noção de personalidade é complexa. A psicologia científica se esforçou no sentido de destacá-la completamente de suas origens metafísicas, mas, como acontece em casos análogos, acabou por desembocar em definições bastante divergentes".

Com isso, já nas estruturas da psicologia e da psiquiatria, Lancan vê dois riscos muito grandes quanto a composição da personalidade. Muito similares ao enquadramento da personalidade que o direito faz sobre positivismo e jusnaturalismo, o autor em comento diz a 
personalidade apresenta em muitas analises acadêmicas a aplicação relativa ao primeiro (positivismo no direito) com uma necessidade de experiência do conceito para sua universalização e depois (jusnaturalismo no direito) com uma aproximação metafísica de legitimidade do conceito que se priva de conceituação científica, vejamos:

As dificuldades estão na dependência de dois riscos. O primeiro é o de uma contaminação sub-reptícia por implicações metafísicas que estão na própria natureza do espírito (...) O segundo risco ameaça aqueles que, prosseguindo com o conhecimento de causa a extração de todo resíduo metafísico, acabam por perder de vista a realidade experimental, que as noções confusas da experiência comum recobrem, e são levados a reduzi-los a ponto de a tornarem irreconhecível ou, ao extremo, de a rejeitarem totalmente. (LACAN, 2011, p. 23-24)

Portanto, a unificação do problema da dupla natureza da personalidade, apesar de na seara da psicologia passar como um erro metodológico, no direito apresenta-se sem distinção específica, apresentado a resolução de problemas na própria poiese jurídica.

Entretanto, o que parece ser paradoxal a primeiro momento, passa a ser mais compreensível ao, desde já, partirmos para o referencial atribuído ao presente trabalho. Em Water Benjamin podemos observar uma relação muito intrínseca entre o positivismo e o jusnaturalismo, não quanto a sua natureza, como tenta fazer a teoria dos direitos da personalidade, mas quanto a sua justificação quanto a validade de sua finalidade, ou seja, a justiça devida ao bem jurídico tutelado.

No texto benjaminiano de 1920 denominado "Zur Kritik der Gewalt” (Benjamin, 1991) na melhor tradução brasileira por João Barrento na obra "O anjo da história" (2019), que leva o título de "sobre a crítica do poder como violência", o autor observa que tanto no direito natural quanto no direito positivo a justiça apresenta-se como

\footnotetext{
Segundo nota do tradutor: O termo alemão usado por Benjamin neste título (Gewalt)
} designa tanto "poder" como a "violência". (BARRENTO in BENJAMIN, 2019, p. 57) 
critério de fins e, é nos meios que se modifica os critérios de observação das passagens, mas existe um meio comum, ou segundo o autor, um dogma fundamental comum que, ainda que sua justificativa se mova sobre o aspecto intrínseco do direito natural e axiológico do direito positivo, os fins justos deverão ser alcançados por meios legítimos, e meios legítimos, aplicados para alcançar fins justos, apresentando-se, assim, os fins como uso de ambos os modelos de direito, como busca de critério comum de justiça, em que, em ambos os casos se justificam por meio do fim a atribuição valorativa dos meios.

O direito natural aspira a "legitimar" os meios pela natureza justa dos fins; o Direito positivo busca "garantir" a natureza justa dos fins pela legitimidade dos meios. A antinomia revelar-se-ia insolúvel no caso de o pressuposto dogmático comum ser falso, ou seja, se os meios legítimos, por um lado, e os fins justos, por outro, se encontrassem numa contradição inconciliável. Mas a percepção desse estado de coisas não seria possível antes de sair do círculo e de estabelecer critérios independentes, tanto para os fins justos como para os meios legítimos. (Benjamin, 2019, p. 61)

Assim, observando que a detenção do poder/violência do direito se dá pela definição a posteriori do fundamento teleológico do bem jurídico delimitado, pode-se justificar aqui a busca dos direitos da personalidade em terem uma tentativa de natureza mista quanto sua definição jurídica.

O problema é, que afinal, com essa conclusão apenas observamos o problema do direito da personalidade como manutenção de uma autopreservação do direito, como ordem determinada pela sua radicalização de sobrevivência, em qualquer que seja sua natureza observada. Isto é, ainda que possamos determinar o fundamento possível de observação quanto a finalidade da personalidade como forma jurídica para manter sua estrutura como meio de garantia de direitos, a sua aplicação torna-se inviável se incompatível com a dogmática jurídica aplicável. 
Esse segundo problema tem outra justificação, a incompatibilidade de elementos intrasubjetivos como personalidade serem categorizados em uma linearidade histórica, elemento que a racionalidade é obrigada a observar. Isso apresenta-se, pois, a personalidade é revelação de interesse da revelação do sujeito quanto a si mesmo, enquanto o direito dessa personalidade é observado a partir da relação historicista com a relação entre contrato e sujeito de direito. O tempo do direito da personalidade é mecânico para sua identificação, enquanto, ao menos da perspectiva do presente ensaio, o tempo da personalidade se traduz por um Agora.

\section{A HIERARQUIA DA PERSONALIDADE NO PROGRESSO NO TEMPO: A TESE XVII}

"Os insignificantes cinco milênios do Homo sapiens", diz um biólogo da nova geração, "correspondem, em comparação com a história da vida orgânica da Terra, a qualquer coisa como dois segundos no fim de um dia com vinte e quatro horas. E toda a história da civilização humana, se a inseríssemos nesse registro, mais não seria do que um quinto do último segundo da última hora". O Agora (Jetztzeit), que, como modelo do tempo messiânico, concentra em si, numa abreviatura extrema, a história de toda a humanidade, corresponde milimetrimente àquela figura da história da humanidade no contexto do universo. (BENJAMin, 2019, p. 20)

Nessa pragmática e, ao mesmo tempo, mística tese de Walter Benjamin, das teses "sobre o conceito de história", temos diversas estruturas a serem observadas que auxiliarão a abrir um novo espaço de análise da personalidade para o direito para além do binômio do Positivismo vs. Jusnaturalismo.

Inicialmente é importante destacar que a composição dialética adotada por Benjamin na tese XVII tem um sentido interessante quanto nos aproximamos do conceito do Agora (Jetztzeit), ligação direta 
com a ideia da abertura de um espaço messiânico para a dominação do direito.

Esse espaço messiânico, ao que nos parece apresentar, em toda sua estrutura mística do judaísmo que a estrutura benjaminiana aplica ao poder, faz uma referência bem delimitada aquilo que podemos apresentar como um espaço, real, positivo, não metafísico e terreno do conceito de glória sobre as escrituras teológico-judaicas.

Esse sentido nos parece interessante na sua relação com o direito pela oposição, justamente o que até então, nos debates de Kelsen e Carl Schmitt se apresentada como normalidade e exceção. Isso porque aos olhos de um espaço messiânico benjaminiano, até o espaço excepcional schmittiano se aplicaria por meio de um racionalismo secular normativo, ou seja, não haveria excepcionalidade de fato na genealogia da exceção, o que haveria seria uma contradição da história linear a ser contada pela democracia liberal da normalidade com a história linear contada a partir do autoritarismo teológico-político.

No espaço messianico temos uma apresentação de um efetivo (virklichen) estado de exceção, uma vez que a partir de uma tradição gnostico-astrológica, ou ainda mesmo em um judaismo rabinico, sobre professias apocalipticas, ha a ideia de que o tempo do messias é marcado com um rompimento real mas não temporal do sistema de interpretação de si para fora, que é feita por uma estrutura de irreconhecimento da linha fenomenologica.

Podemos observar, por exemplo, ainda referenciando a ideia no livro I do Apocalipse sírio de Baruque, no Capítulo 28, em que a ideia de que os monstros apocaliticos devorarão os impios à carne, ou seja, ainda no tempo do messias o tempo, conquanto seja paralizado no sentido mecanico, o sujeito permanece, mas referido agora como alma, conforme se expressa, no Capítulo 29 da mesma obra:

Terminado o tempo vigente do Messias, Ele voltará de novo à g lória do céu. Então haverão de ressuscitar todos aqueles que outrora adormeceram na sua esperança. Naquele tempo acontecerá que se abrirão as câmaras onde se demoram as almas 
dos piedosos; elas sairão, e todas essas numerosas almas, como legião de um só coração, aparecerão todas juntas, abertamente. As que foram as primeiras, alegrar-se-ão; as que foram as últimas, não estarão tristes. Cada uma delas sabe que foi chegado o tempo, previst o como o fim de todos os tempos. As almas dos pecadores perder-se-ão em angústia, ao presenciarem tudo isso. Pois elas já sabem que o tormento as atingirá, e que a hora da sua condenação é chegada. (Zanata (org), 2014, p.82)

É interessante observar que no intervalo destes dois capítulos, o pensamento gnostico primitivo apontava por uma interpretação revelatória da persona em vida, ou seja, uma em corpo no tempo e outra em corpo no messias, essa chamada de alma, ou seja, há uma possível definição de encontro com o sujeito para seu espaço de abertura no tempo do messias, em que sua individualidade, ou seja, personalidade, agora se revela fora de um espaço determinado o qual busca a individualidade no tempo, e suas nuances, mas com o rompimento do Kosher, e sua estrutura de lei mosaica, a persona do sujeito agora, ainda que em corpo pode se determinar como uma realização de alma, de forma que essa alma representa seu corpo desalinhado com a objetividade da tentativa universal de controle legal, ainda que pela visão de Moisés.

Com isso, a excepcionalidade não repousaria na forma estrutural relacionada ao direito, mas de fato, na forma messianica de como o sujeito se relaciona com a norma, com isso não haveria possibilidade de se pensar em um espaço excepcional do direito uma vez que sua referencia ainda seria o proprio direito. O espaço messiânico por sua vez rompe com qualquer estrutura normativa, com isso apresenta-se por meio do Agora, não designado pelo passado ou futuro, mas no espaço efetivo de exceção sobre o sujeito.

A efetividade de tal estado de exceção aparece, ainda nas teses sobre o conceito de história, na famosa tese VIII, quando Benjamin afrima que a tarefa concreta dos oprimidos repousa na necessidade de “provocar o verdadeiro estado de exceção” (BENJAmin, 2016, p. 13), 
que, para nós a melhor tradução não seria verdadeiro, mas efetivo, a partir do termo wirklichen. ${ }^{2}$

Mas para isso seria necessário que retornemos agora na perspectiva da tese XVII.

Benjamin atribiu uma relação por um lado objetiva e por outro messianica em relação ao tempo. Por um lado apresenta uma estrutura apresentada pelo jovem biólogo sobre o tempo da humanidade perante o tempo de existencia histórica do universo.

Por outro lado ao relacionar a história da humanidade a partir do Agora, ele deixa esta humanidade em referencia exata (milimetrica em espaço) com todo o tempo histórico da vida orgânica.

Essa relação é muito interessante para a determinação do local do indivíduo em um espaço messianico. Observe-se que quando a referencia é liogada a um tempo mecânico, linear, ou seja, a partir de um historicismo, há uma necessidade hierarquica com as relações intramundanas na histórica. A insignificancia do Homo sapiens frente a vida organica é observada a partir da legitimidade de tempo histórica entre eles. Ou seja, a partir de uma perspectiva de legitimidade histórica, o progresso é o ponto de referencia entre aquilo mais ou menos legítimo a partir da leitura progressiva do tempo. A vida organica se apresenta na história com um progresso demasiadamente mais refinado do que a vida humana, que tem, por certo, muito menos tempo mecanico de desenvolvimento linear de sua estrutura legitimadora.

Essa referencia do autor tem um sentido essencial sobre o rompimento temporal do espaço messianico, uma vez que, ao quebrar a

2 É importante observar a relação específica que Benjamin usa nessa afirmação de conteúdo específico do que seria o espaço messiânico. Em seu original ao se referir a este estado de exceção e sua efetividade o autor utiliza o termo "wirklichen ausnahmezustan", a escolha desse termo, nos parece uma referência direta a obra "Grundlinien der Philosophie des Rechts" de Hegel, uma vez que este traz o famoso conceito de que "Was vernünftig ist, das ist wirklich ; und was wirklich ist, das ist vernünftig” (HEGEL, 1989, p. 24) - ou em tradução livre: "o que é efetivo é real; e o que é real é efetivo", ou seja, a realidade apresentada em Hegel, para a visão bejaminiana se reproduz em um Estado de Exceção não normativo, ou seja, de dever-ser puro, mas na efetivada do sujeito sobre o seu fenômeno. 
barreira do tempo linear e progressivo, o autor apresenta então uma equiparação, até então impossível, entre a legitimidade atribuida pelo progresso do tempo e o indivíduo lido fora dele, a partir de um tempo específico em que o autor chamará de Agora.

Em um de seus manuscritos, catalogados no Arquivo Benjamin e numerado como "manuscrito 471", que o autor intitula de "Das Jetz dere Erkennbarkeit" - ou "o agora da possibilidade de conhecer", Benjamin observa o trabalho do historiador como profeta, afirmando que de forma tradicional este tem por objetivo transpor-se a um passado em que se profetizava ainda o que era futuro, esquecendo assim o que se passou depois dela, ou seja, tentar fazer o exercicio de se furtar de sua experiencia historica para a comrpeensao do passado, entretanto, para explicar o que este considera uma verdade arqueologia da história o autor afimar:

O historiador volta costas ao seu proprio tempo, e seu olhar de vidente inflma0se com os cumes dos acontecimentos de gerações humanas anteriores, progressivamente mais mortiços à medida que vão merguhando mais no passado. Esse olhar de vidente tem do seu proprio tempo uma consciencia mais nítida do que os contemporaneos que "acompanham" esse tempo. Não é por acado que Turgot define o conceito de um presente que representa o objeto intencional de uma profecia como conceito essencial e radicalmente político (BENJAMIN, 2019, p. 183)

Com isso, a proposta benjaminiana é um afastamento do tempo que permita a anlise da história driblando os aspectos nostalgicos invividos do passado e observando fora de uma lineariedade, mas como um horizonte único do momento, ou seja o Agora, não em relação a história, mas em relação ao sujeito que observa, é o sujeito que se relaciona com o Agora da história, revelando os seus objetos de análise fora de uma hierarquisação temporal de importancia adstrita. Assim politiza a história, e não a legitima, ou, assim como afirma o autor, politiza se destinando a prever o presente, com mais observação 
clara do que aqueles presentes na linearidade progressiva. Assim, o momento, seja na história, apresenta-se como uma presentificação de determinado momento.

A ideia é a delimitação do sujeito sobre a perspectiva propria e de consciencia (não racionalidade) do que se admite sobre sua propria existencia. Ao inves de axiologia sobre os elementos progressivos da história, uma observação sobre os conceitos estéticos, de bom, belo e verdadeiro, de sua consciencia presentista sobre o elemento a ser observado, com isso, este elemento apresenta-se, em relação ao sujeito, como um efetivo estado de exceção.

Para isso, observemos, por exemplo, que na VII tese dos conceitos de história de Walter Benjamin, o autor afirma categoricamente que "não há documento de cultura que também não seja um documento da barbárie. Que do mesmo modo que ele não pode libertar-se da Barbarie, assim também não pode o processo historico em que ele transmitiu de um para o outro" (Benjamin, 2019, p.13), com isso, podemos observar, na propria tradução judaica a qual este autor esta ligado, que não faz parte da cultura a definição do que é definido pela historia, esta que se representa como rosto da humanidade, ou seja, a personalidade da humanidade é possivel de ser determinada pela história, entretanto essa mesma história pode se transmutar de sentido dependendo do tempo.

Ora, a história ainda que represente a face da humanidade, tem suas metamorfoses, do rosto glorioso ao rosto desfigurado, veja-se, num exemplo cultural, o aclamado longa-metragem fundador do cinema moderno, denominado no brasil como "o nascimento de uma nação", nele a gloria ariana se representa na história como o rosto erigido do belo e verdadeiro, entretanto a persona da história moderna, vê naquele rosto um dano, uma transmutação, uma metamorfose bestial. Com isso a historia, ainda que para ser determinada por uma via do progresso passa pelo prossedimento da bestialidade do rosto.

Com isso, podemos observar que, quando benajmin se refere ao documento, a persona da história se revela pela bestialidade, e o juízo 
não esta no progresso, mas no progresso se observa a necessidade da bestialização cultural para revelação da personalidade do tempo. Só há personalidade cultural e individual no tempo, a personalidade é essencial para o progresso, pois é no complexio oppositorum que a estética do persona é definida, o belo e o feio fazem-se no instrumento historico do progresso linear, ou seja, só há personalidade se relacionada primitivamente ao tempo, e ao tempo mecanico, presente, solipsista e nada existencial. Já na tradição messianica, não há besta, pois o teromorfismo da arte medieval nos revela que a representação do tempo do messias é a impotencia da estética do belo sobre a apreensão da personaldiade. A persona no tempo do messias, pelo menos na tradição rabinica e gnóstica, se dá por uma universalidade não progressiva, mas acentuada fora do tempo mecanico, sobre o que se apreende. A personalidade pode ser portanto presente no progresso, uma vez dependendo da cultura e definindo a resolução do tempo da história, de forma que é essencialmente cultural e muito prejudicada de sua categoria jurídica, já fora do tempo a personalidade é uniforme quanto a sua prescindibilidade de acompanhamento do progresso temporal.

Por isso, o caráter de exceção e normalidade só são possiveis de serem definidos dentro do tempo do progresso, uma vez que este tempo, nos permite uma antípoda conceitual impossível de examinar-se na tradição do tempo messianico, que é a noção de norma e exceção.

O que parece em um primeiro momento indissociável, que é a separação do progresso histórico-tecnológico com o progressismo, em Benjamin tem uma um abismo, que pode ser revelado por um elemento messiânico, ou ainda mais forte, por um romantismo revolucionário que observa no presente o belo como verdade, o trágico como rompimento do tempo mecânico. Entrementes, é justamente o progressismo que esbarra na forma do tempo operativo, como conteúdo dogmático, a técnica não se sustenta na história e no progresso, mas sobre a função mecânica de tempo em que o progresso se funde ao intervalo de tempo e é usado como justificativa a própria reprodução do tempo. 
Observemos, por exemplo, no manuscrito 475 de Benjamin, quando este afirma categoricamente que "não há progresso na arte, do ponto de vista de seu elemento profético" (Benjamin, 2019, p. 185). A partir disso observamos que quando há uma espaço estético em que o critério a ser delimitado pelo indivíduo não é o progresso extraterrano como legitimidade, mas a função intrasubjetiva de observação de sua estrutura de que delas fazem parte do indivíduo. E dentre estas questões abertas sobre o Agora, quanto a critério de observação que não se escalona a partir da ideia de progresso, mas da presentificação do sujeito, é justamente sua personalidade.

A persona no tempo aberto do messias é uma reconciliação com a universalidade fora da lei, ou seja, a animalidade perde seu sentido de besta e passa a se confundir com a representação humana, uma vez que a criação do messias traz ao homem a semelhança a si mesmo, de forma que a diferenciação, ou o gesto de diferenciação da prática da personalidade na sociedade de um tempo mecanico se encerra, agora a diferença não é mais cultural ou individual, ela só se faz sobre paradgmas religiosos, com isso a cultura não determina a personalidade, mas sim a raiz romantica do sujeito quanto a sua propria existencia, a persona aqui não é mais a mascara do sujeito, mas o rosto quase acéfalo dos individuos, uma vez que a regressão a si passa pela inutilidade do passado e permanencia nostalgica do futuro.

\section{A PERVERSÃO DO TEMPO E A CONTRA-GENEALOGIA DO DIREITO DA PERSONALIDADE: A TESE XVI}

O materialista histórico não pode prescindir de um conceito de presente que não é passagem, mas no qual o tempo se fixou e parou. Porque esse conceito é precisamente aquele que define o presente no qual ele escreve a história para si. O historicismo propõe a imagem "eterna" do passado; o materialista histórico faz desse passado uma experiência única. Deixa aos outros o papel de se entregarem, no bordel do historicismo, à prostituta 
chamada "Era uma vez". Ele permanece senhor das suas forças, suficientemente forte para destruir o contínuo da história. (Benjamin, 2019, p. 19)

Esse fragmento, certamente um dos mais reveladores da estrutura da ideia de tempo no pensamento benjaminiano, traz uma possibilidade complementar a ideia anteriormente apresentada sobre a abertura de uma exceção efetiva por meio de um tempo messiânico para o reconhecimento, ou ainda, a apreensão da personalidade como estatuto passível de identificação, coisa que o direito não foi capaz ainda de fazer, se rendendo a uma metafísica da personalidade e uma moralização do indivíduo como meio de garantir a adequação de um conceito misto quanto a seu meio, para justificar um fim por meio de uma atuação jurisdicional.

A ideia apresentada mostra uma perversão do progresso em relação ao tempo, a analogia a prostituição do "Era uma vez" pode indicar uma pista sobre a revelação poiética do estatuto de um Agora para a revelação do sujeito. Dentro do espaço do direito, a relação entre o historicismo e a racionalidade, validando a opção mais realizável da universalidade a partir da observação "para trás" da objetividade dos fatos, não a partir de dirimir o indivíduo, mas de uma despersonalização de um elemento normativo, que aparece apenas como caráter legitimador do tempo que progride o direito.

O progresso, é elemento essencial para existência desse direito, uma vez que progresso é intimamente ligado com a relação de evolução entre situação genealógica e desenvolvimento perseptivel, ou seja, o progresso implica num elemento legitimador do tempo normativo, a relação do ponto inicial e do presente não se deslocam, mas se mantem ligados, de forma que o presente não é o momento, mas o composto da realização apreensível do ponto de partida.

Com isso, o indivíduo não se legitima em si, mas se submete ao passado por meio da observação da experiência, seu agora nada mais é que uma comparação da fórmula que o faz olhar para o passado, de 
forma que não observa o presente, apenas o deglute sob a comparação daquilo que se deve conservar.

Com isso, o progressismo político, baseado na linearidade e historicidade do tempo pouco tem de progressista, na verdade é tão conservador quanto todo movimento que, ainda que secularizado, teologize a política, isso porque a relação do passado como ponto de partida de observação ao progresso constitui uma linha instransponível de conservação da genealogia do objeto legitimado pelo direito.

Portanto, o direito relacionado ao progresso é tão reacionário ao ponto de, sob o pretexto do progresso, constitui a linha temporal de desenvolvimento para marcar o ponto de início e conservá-lo como perspectiva, e isso se chama racionalismo.

Observa-se que os salvacionistas do direito moderno, assim como habermasianos e os ligados a doutrina estadounidense de direito, a partir de Dworkin passaram a estatuir a linha linear de observação ao direito, para assim passar sua legitimidade racional a decisão judicial. A teoria do romance em cadeia deste citado, por exemplo, constitui o limiar da racionalidade a partir de um envolvimento conservador com o ponto inicial da racionalidade jurídica. A modernidade, portanto, se exprime pela conservação do progressismo, não quanto ao seu fim, mas quanto ao seu ponto de partirda, sendo o telos uma resposta inalcançável de observação daquilo que se obteve primeiro.

Com isso, por exemplo, a estatuir a liberdade como norma fundamental da estrutura legitimadora do direito, o Estado político a partir do historicismo, observa liberdade como um elemento de progresso, entretanto a liberdade do Agora não se apresenta. Apenas pode-se observar o ponto de referência, qual seja a liberdade pensada no ponto despersonalizador que constitui uma ordem estatal, isso pode ser observado no texto de Walter Benjamin, já citado anteriormente, "sobre a crítica do poder como violência" (BENJAMin, 2019, p. 67):

Do mesmo modo que não devemos poupar a críticas essa ordem, que o Direito, com razão, pretende conservar, assim 
também qualquer contestação dessa ordem se revela impotente em face da crítica, se for feita apenas em nome de uma "liberdade" sem forma, sem possibilidade de referência àquela ordem superior de liberdade. [...] Porque o poder que tende a preservar o Direito é um poder ameaçador. Essa ameaça porém não deve ler-se no sentido de intimidação, como acontece com certos teóricos liberais desinformados

De fato, conforme observa o autor, o poder que tende a preservar o direito não intimida justamente porque ele repousa no historicismo, ou seja, na perversão da relação do passado com um presente não perceptível. O sujeito prostituído com o tempo mecânico não pode observar o que significa seu direito no Ágora, justamente porque a ameaça do não direito se dá no agora, ou seja, na percepção niilista do sujeito, no complexio oppositorum da revelação do mal, enquanto é na nostalgia de seu direito que há a garantia do cumprimento e validade.

Como já adiantado no tópico anterior, existe, para abertura de um espaço messianico e da percepção da personalidade como direito no Ágora pelo sujeito, uma necessidade estética, onde o rompimento com a percepção extrasubjetiva de validade do progresso se substitui pelo reencontro com o belo para formação de um verdadeiro que não é passagem.

Para isso, é necessário observar, em Benjamin, seus fragmentos de arte, dentre eles "A obra de arte na época da possibilidade de sua reprodução técnica" trata-se de um primoroso texto que em suas entrelinhas nos ensina elementos essenciais para o alcance de uma abertura do Agora para uma exceção efetiva do tempo messiânico.

No texto, sob o pretexto da observação de como se comporta a observação social em relação arte em um momento que sua reprodução é possível por meios tecnológicos, o autor questiona-se que por mais "perfeita que seja a reprodução, uma coisa lhe falta: o aqui e agora da obra de arte - a sua existência única no lugar onde se encontra. Sobre essa existência única, e sobre ela apenas, se fez a história a que 
a obra esteve sujeita no decurso de sua existência." (Benjamin, 2017, p.13). Com isso podemos observar uma relação da estética da obra, ou seja, com um espaço romântico de desapropriação do tempo que sua observação de verdade se constitui não no tempo mas no belo, uma vez que fora do "aqui e agora", a obra passa a ser um objeto diverso daquele uma vez observado.

Isso, claro, se deve a condições físicas, mas mais que isso, não significa dizer que a existência da obra não é apreciável fora do tempo em que se encontrou, mas sim, que seu tempo só pode existir fora de um progressismo mecânico de determinação, uma vez que se constitui no belo, seu verdadeiro não pode ser registrado por meio de um prosseguimento temporal, pois a ela faltarão seus elementos mais específicos, quais sejam, sua personalidade que, por ser estética, não se traduz na racionalidade, portanto, necessita que sua observação seja um presságio messiânico do Agora, ainda que, no tempo progressivo, seja diverso do momento de sua feitura. Tanto que, a própria obra não se traduz sobre sua feitura em um único tempo, cada momento de sua elaboração constitui seu próprio tempo progressivo, porém, sua realização de verdade, se constitui no belo, assim, divergindo da percepção mecânica que a coloca em um ponto inicial, de forma que olhar para tal imagem com uma corrente que a apreende em um ponto inicial, legitima sua hierarquia valorativa, mas distancia sua experiência estética.

A possibilidade de reprodução técnica da obra de arte transforma a relação das massas com a arte. Uma relação o mais retrógrada possível, por exemplo, diante de um Picasso, pode transformar-se na mais progressista, por exemplo diante de um Chaplin. Aqui, a relação progressista caracteriza-se pelo fato de o prazer da observação e da vivência estar direta e intimamente associado à atitude do perito. Tal ligação é um indício social importante: quanto mais diminuir o significado social de uma arte, tanto mais haverá no público um divórcio entre a atitude crítica e o prazer - como se prova nitidamente com a pintura. (Benjamin, 2017, p. 35) 
Veja-se que Benjamin aqui nos dá um indício claro que o significado social da arte não tem relação direta com o seu tempo, mas com o objeto da vivência da obra. Assim como no espaço de exceção efetiva do tempo messiânico, ao qual se relaciona o direito da personalidade, a obra de arte não pode ser deduzida a partir de uma relação entre pontos lineares, ela é apenas um ponto de observação excepcional.

Crítica e prazer tem relações efetivamente diversas, assim como a personalidade no direito, como demonstramos, a primeira é racionalizante e a segunda é intrasubjetiva, o casamento desses dois elementos parece, a primeiro momento, metodologicamente incompatível, entretanto, ao observar sem referência de legitimação temporal, ambos elementos se realizam não segundo um ponto de observação de validade, mas do objeto em si, o prazer é crítico, pelo ente social, no momento que esse ente sai de seu particípio presente e seu infinitivo passa a estar diretamente ligado ao Agora.

O tempo, portanto, dentro do progressismo é prostituído por sua característica de ser forma, seu conteúdo não se ostenta em si, como na prostituição que o objeto do prazer é a forma do contrato, no tempo a mesma coisa se adverte, uma vez que não há espaço para um tempo racionalizado.

Por isso, justamente nesse sentido, o tempo progressivo e linear apresenta contradição inclusive com sua estruturação da percepção tridimensional física, isso porque a percepção do tempo deve se ligar ao espaço, enquanto o tempo mecânico se liga ao progresso e desconsidera o espaço em que o ponto de partida se relacionou, apenas se realiza na legitimação de seu caráter de arché. Com isso Benjamin, em sua tese XIV, respaldaria essa afirmação quando em sentido mais estrito afirma que a história "é objeto de uma construção cujo lugar é constituído não por um tempo vazio e homogêneo, mas por um tempo preenchido pelo Agora (Jetztzeit)" (Benjamin, 2019, p. 18). Com isso o conteúdo do tempo se preenche pela forma do espaço, o conteúdo se apresenta justamente na ligação pura entre o indivíduo e a física perseptivel, o Agora é o único elemento que resgata o sujeito de 
sua alienação relativista da racionalidade, apresentando a ele a relação direita com sua personalidade, aqui então possível de se determinar.

O desligamento do sujeito com o tempo progressivo é um rompimento que pode revelar na personalidade do sujeito qualquer movimento que este necessite por sua própria observação, por isso é o loco ideal de percepção sobre os aspectos normativos, não em sentido positivista, mas em sentido messianico, de sua existência como persona. Justamente isso, pode fazer da necessidade mais profana daquele indivíduo um espaço de determinação da realização livre e consciente de si. Não racional, mas consciente.

Isso, podemos observar, ainda que com ressalvas e cuidado, em um dos textos mais complexos, metafóricos, místicos e paradoxais de Walter Benjamin, denominado "Fragmento teológico-político", mas que pode nos trazer ricas observações em um fragmento selecionado, o qual citamos:

A ordem do profano tem de se orientar pela ideia da felicidade. A relação dessa ordem com o messiânico é dos axiomas essenciais da filosofia da história. De fato, essa relação determina uma concepção mística da história cuja problemática se pode apresentar através de uma imagem. Se a orientação de uma seta indicar o objetivo em direção ao qual atua a dynamis do profano, em uma outra a direção da intensidade messiânica, então não dúvida de que a busca da felicidade pela humanidade livre aspira a afastar-se da direção messiânica; mas do mesmo modo que uma força, ativada num certo sentido, é capaz de levar outra a atuar num sentido diametralmente oposto, assim também a ordem profana do profano é capaz de suscitar a vinda do reino messiânico. (Benjamin, 2019, p. 24)

Quando, na tese XVI, objeto de análise deste tópico, observamos a ideia de que a "eternidade" do passado pode ser observada pelo sujeito como senhor das suas forças contra o contínuo da história, temos aqui nesse fragmento acima uma realização, mística, mas bem consciente, do que isso significa. 
Se, de um lado o sujeito, senhor de seu poder é uma ameaça a própria ordem, que o direito preserva, e sua personalidade é justamente o elemento que dá a ele os traços reconhecíveis de seu comportamento, essa personalidade é, portanto, a profanação de um espaço de realização da verdade do belo, mas isso levaria necessariamente a verdadeira legitimidade do direito. Mas diversamente, é justamente no profano da personalidade, destruidora e emancipadora do contra-direito, que o espaço messiânico pode se revelar, uma vez que fora do tempo do progresso, ou seja, das referências observáveis de legitimação do direito como verdade, se expõe o belo da personalidade que a faz realizar-se com o misticismo do indivíduo frente a sua própria existência, as necessidades deste sem as relações de observação temporal.

A personalidade é, por meio da definição no espaço da forma jurídica, assim como no espaço do conteúdo naturalista, um elemento que se legitima não pelo sujeito, mas sobre o possível elemento do sujeito que deve ser preservado, não pela sua potência, mas pela sua necessidade de expressão de vivência.

Entretanto essa vivência é legalmente relacionada com uma ordem específica que dedica sua observação a partir da legitimidade do progresso temporal, ou seja, a personalidade não é do indivíduo é do sujeito de direito. O indivíduo quando observado pelo direito sob o aspecto de sua personalidade como medida de traço de caráter apresenta-se, portanto, em um limiar de observação, que, pelo contrário não o dá direito, mas obrigação. Observemos então um fragmento do texto de Walter Benjamin intitulado “destino e caráter”:

Destino e caráter são muitas vezes vistos em ligação causal, sendo o caráter referido como causa do destino. O que está subjacente a essa ideia é o seguinte: se, por um lado, o caráter de uma pessoa, ou seja, também o seu modo de reagir, fosse conhecido em todos os seus pormenores, e se, por outro lado, o acontecer universal fosse conhecido nos domínios em que se aproxima daquele caráter, seria possível prever exatamente tanto o que aconteceria a esse caráter como o que ele seria capaz de realizar (BENJAMin, 2019, p.49) 
É nessa hipótese que a referência legitimadora do tempo observa a personalidade não jurídica do sujeito de direito, por um ponto de referência relativa ao progresso, o caráter que é um traço da personalidade, não pode ser referenciado como mudança justamente porque a norma interferiu para que a forma de personalidade fosse definida a partir de suas combinações para um fim comum, independente dos meios, de forma, que assim não fosse mais possível observar o desenvolvimento da personalidade como caráter, dando a ele um elemento de destino determinado.

Portanto, não se pode atribuir a personalidade um elemento de poder que intimide a função do poder do direito, uma vez que o rompimento da personalidade nulifica esses elementos universais de poder, podendo fazer com que o indivíduo alcance o espaço místico de si mesmo, de forma que revele sua personalidade por meio do Agora, que é justamente o direito que a esta personalidade é reservado.

\section{CONCLUSÃO}

Conforme foi apresentado, o presente trabalho propôs uma análise de uma analisa inicial de um binômio que repousa na possibilidade de observação dos Direitos da Personalidade no sistema jurídico o qual são propostos. Isso porque dentro do modelo democrático parlamentar, de Estado de Direito, ainda que se observe tentativas de reforma do método aplicável a atividade jurisdicional toda sua estrutura é medularmente positivista, o que significa necessariamente observar a personalidade como direito normativa puro em um plano de dever-ser.

Entretanto esse mesmo direito, por sua ambígua capacidade de análise apresenta-se tendência, na própria forma de realização de sua estrutura decisional pela jurisdição um caráter de busca de inerência ao sujeito, o que faz dele uma natureza relacionada com um juspositivismo elementar. Essa contradição tem uma consequência disforme, apresentar num sistema de despersonalização onde o indivíduo é reduzido ao seu conjunto de normas de formação do sujeito de direito a uma essencialidade incompatível com o ato normativo. 
Entretanto, como se pode observar essa relação pode ser justificada em um ponto em que seus meios de legitimação se confundem para realização da finalidade de preservação do direito, entretanto com isso a personalidade passa a não ser um elemento de observação objetiva, uma vez que seu progresso temporal é medido pela sua experiência fundamental no direito.

Como rompimento a isso foi apresentado, a partir de duas teses sobre o conceito de história de Walter Benjamin a possibilidade de abertura desse espaço temporal de relação a partir do caráter do Agora, com a formação do chamado tempo messiânico.

A personalidade nesse paradigma não mais se apresenta no progresso da linearidade do tempo mecânico, isso porque esse tempo implica não em uma evolução, mas em uma desconsideração da atividade da apreensão da personalidade do indivíduo a partir de si, mas sim a partir de uma hierarquização de conduta temporal que liga o presente em um ponto fixo no passado, com isso a identificação do presente fica prejudicada pela referência do passado para uma fórmula de resultado do progresso.

O tempo messiânico, portanto, em Walter Benjamin, apresenta uma possibilidade teórica de enfrentamento da personalidade como um direito do indivíduo não a partir de sua validade, mas sim, a partir de sua representação de verdadeiro por meio da representação do belo eterno.

Em outras palavras, a racionalidade do tempo substitui-se pelo conhecimento do ato em si, que revela não a marcação do traço do sujeito pela sua personalidade comparada em um ato universal, mas sim, o direito que o representa a partir do Agora, sob o aspecto político de localização do espaço em que esse se diagnostica como verdade.

\section{REFERÊNCIAS}

BENJAMIN, Walter. Estética e sociologia da arte. Trad. João Barrento. Belo Horizonte: Autêntica Editora, 2017 
O anjo da história. Trad. João Barrento. 2ed. Belo Horizonte: Autêntica Editora, 2019.

Zur Kritik der Gewalt. Frankfurt: Suhrkamp-Taschenbuch, 1991.

FEIST, Jess; FEIST, Gregory J.; ROBERTS, Tomi-Ann. Teoria da personalidade. 8. ed. Trad. Sandra Maria Mallmann da Rosa. Porto Alegre: AMGH, 2015.

FELIX, Diogo Valério. ÁVILA, Gustavo Noronha. Os reflexos da educação à distância no brasil como política pública de efetivação dos direitos de personalidade in RJBL, ano 6, nº, 2020.

HEGEL, Georg W.F. Wirke 7 - Grundlinien der Philosophie des Rechts oder Naturrecht und Staatswissenschafl im Grundrisse. Suhrkamp-Taschenbuch, 1989.

LACAN, Jaques. Da psicose paranoica em suas relações com a personalidade. 2ed. Rio de Janeiro: Forense Universitária, 2011.

SIQUEIRA, Dirceu Pereira; ZANINI, Leonardo Estevam de Assis; et.al. Os direitos da personalidade em face da dicotomia Direito Público - Direito Privado. Revista de Direito Brasileira | São Paulo, SP | v. 19 | n. 8 | p. $208-220,2018$

TREPEDINO, Gustavo. A tutela da personalidade no ordenamento civil-constitucional brasileiro in TREPEDINO, Gustavo. Temas de direito civil. Rio de Janeiro: Renovar, 1999.

ZANATA, Gabriel (org.). Apócrifos II - Apocalipse. 1. ed. São Paulo: Zanata, 2014.

\section{DIRCEU PEREIRA SIQUEIRA}

Coordenador e Professor Permanente do Programa de Doutorado e Mestrado em Direito da Universidade Cesumar, Maringá, PR (UniCesumar); Pós-doutor em Direito pela Faculdade de Direito da Universidade de Coimbra (Portugal), Doutor e Mestre em Direito Constitucional pela Instituição Toledo de Ensino - ITE/Bauru, 
Especialista Lato Sensu em Direito Civil e Processual Civil pelo Centro Universitário de Rio Preto, Pesquisador Bolsista - Modalidade Produtividade em Pesquisa para Doutor - PPD - do Instituto Cesumar de Ciência, Tecnologia e Inovação (ICETI), Professor nos cursos de graduação em direito da Universidade de Araraquara (UNIARA) e do Centro Universitário Unifafibe (UNIFAFIBE), Professor Convidado do Programa de Mestrado University Missouri State - EUA, Editor da Revista Direitos Sociais e Políticas Públicas (Qualis B1), Consultor Jurídico, Parecerista, Advogado.

Endereço profissional: Universidade Cesumar, Av. Guedner, 1610 - Jardim Aclimacao, Maringá - PR, 87050-900, Brasil.

ORCID: https://orcid.org/0000-0001-9073-7759

E-MAIL:dpsiqueira@uol.com.br

\section{FAUSTO SANTOS DE MORAIS}

Doutor em Direito (UNISINOS), Docente da Escola de Direito e do PPGD IMED, Editor Chefe da Revista Brasileira de Direito (RBD) e da Revista Brasileira de Inteligência Artificial e Direito (RBIAD), Fundador da Associação Ibero Americana de Direito e Inteligência Artificial (AID-IA), pesquisador com fomento da Fundação Meridional, Advogado.

Endereço profissional: Faculdade Meridional - IMED, R. Gen. Prestes Guimarães, 304 - Vila Rodrigues, Passo Fundo - RS, 99070-220, Brasil.

ORCID ID: https://orcid.org/0000-0002-4648-2418

E-MAIL: faustosmorais@gmail.com

\section{FERNANDO RODRIGUES DE ALMEIDA}

Doutorando em Ciências Jurídicas pelo Centro Universitário de Maringá, como bolsista CAPES/PROSUP, sob orientação do Prof. Dr. Dirceu Pereira Siqueira; Mestre em Direito pelo Centro 
Universitário Eurípides de Marília, como bolsista CAPES/PROSUP, sob orientação do Prof. Dr. Oswaldo Giacóia Junior; Graduado em Direito pelo Centro Universitário Eurípides de Marília; Coordenador e Professor de Filosofia do Direito e Direito Constitucional no Curso de Direito Das Faculdades Maringá. Líder do Grupo de Pesquisa Direito e Memória (DiMe/Faculdade Maringá).

Endereço profissional: Universidade Cesumar, Av. Guedner, 1610 - Jardim Aclimacao, Maringá - PR, 87050-900, Brasil.

ORCID ID: https://orcid.org/0000-0001-6144-7752

E-MAIL: fernandordealmeida@gmail.com

Recebido: 06/10/2020

Aceito: $30 / 03 / 2021$ 